\title{
Influência do óleo de Copaifera langsdorffii no reparo de ferida cirúrgica em presença de corpo estranho ${ }^{1}$
}

\author{
Rafael C. Vieira ${ }^{2^{*}}$, Ethiane Bombardiere ${ }^{3}$, Julierme J. Oliveira ${ }^{3}$, Ruy S. \\ Lino-Júnior ${ }^{4}$, Luiz A.B. Brito ${ }^{5}$ e Ana P. Junqueira-Kipnis ${ }^{4}$
}

\begin{abstract}
Vieira R.C., Bombardiere E., Oliveira J.J., Lino-Júnior R.S., Brito L.A.B. \& Junqueira-Kipnis A.P. 2008. [Influence of Copaifera langsdorffii oil on the repair of a surgical wound in the presence of foreign body.] Influência do óleo de Copaifera langsdorffii no reparo de ferida cirúrgica em presença de corpo estranho. Revista Pesquisa Veterinária Brasileira 28(8):358-366. Instituto de Patologia Tropical e Saúde Pública (IPTSP), UFG, Rua 235 s/n, Sala 325, Setor Universitário, Goiânia, GO 74605-050, Brazil. E-mail: rafael.objetivo@gmail.com

Copaifera langsdorffii is a Brazilian native leguminosae that produce resin-oil, popularly known as copaíba oil. This oil is used for the treatment of skin wound due to its recognized antiinflammatory and wound healing effects. Despite, its popular use, there are few published data about the therapeutic effect of this medicinal plant. The aim of the study was to evaluate the topic treatment effect of the Copaíba oil on the process of skin repair inflammation induced by a foreign body subcutanously implanted. Sixty BALB/c mice were submitted to a $1 \mathrm{~cm}$ linear incision and a $12 \mathrm{~mm}$ circle coverslip was subcutaneously implanted. Four treatments groups were established: control, sterile saline (C); vehicle control, sterile mineral oil, (VC); treatment 1 (T1), mineral oil plus copaiba oil (V/V), and treatment 2 (T2) copaiba oil. The evaluations were performed at pre-determined time points (1, 3, 5, 7 and 14 days). It was possible to find fibroblasts, epithelial cells proliferation, re-epithelization and newly formed blood vessels in all groups, however, all oil treated groups (T1 and T2) did not present re-epithelization at three days post surgical incision. On days 5 and 7 , a higher intensity of edema and hyperemia on the groups T1 and T2 was observed, besides that, the T1 and T2 groups presented a serous cellular scab on the wounds that was absent on the $\mathrm{C}$ and VC groups. The inflammatory reactions among the groups $\mathrm{C}$ and VC showed more mononuclear cells than the T1 and T2 groups that presented a mixed cell patter composed from both mono and polymorphonuclear cells. Although the surgical wounds were re-epithelizaded, in the groups T1 and T2, they were covered by a serous cellular crust and the dermis tissue still presented an intense mononuclear cell inflammatory focus. Fourteen days after of the surgical incision, the gross aspects on groups C and VC were similar and on groups T1 and T2, despite wound to be completely closed and without crusts, the skin those animals was thickened. Furthermore, the dermis on group T2 presented moderate fibrosis, while the other groups presented slightly ones. The results demonstrated that topical treatment with $C$. langsdorffii oil debilitated the normal process of a wound repair in the presence of a foreign body.
\end{abstract}

INDEX TERMS: Copaifera langsdorffii, copaíba, wound healing, anti-inflammatory.

\footnotetext{
${ }^{1}$ Recebido em 24 de novembro de 2007.

Aceito para publicação em 26 de junho de 2008.

2 Pós-Graduando em Ciência Animal, Escola de Veterinária, Universidade Federal de Goiás (UFG), Campus Samambaia (Campus II), Cx. Postal 131, Goiânia, GO 74001-970, Brasil. *Autor para correspondência: rafael.objetivo@gmail.com
}

\footnotetext{
${ }^{3}$ Graduando em Medicina Veterinária, Escola de Veterinária, UFG, Campus Samambaia, Cx. Postal 131, Goiânia, GO 74001-970.

${ }^{4}$ Instituto de Patologia Tropical e Saúde Pública (IPTSP), UFG, Rua 235 s/n, Setor Universitário, Goiânia, GO 74605-050.

${ }^{5}$ Setor de Patologia Veterinária, Escola de Veterinária, UFG, Campus Samambaia, Cx. Postal 131, Goiânia, GO 74001-970.
} 
RESUMO.- A Copaifera langsdorffii é uma leguminosa nativa do Brasil, da qual pode ser extraído um óleo, popularmente conhecido como óleo de copaíba. Este óleo é amplamente utilizado para tratamento de feridas cutâneas por ser reconhecido como antiinflamatório e cicatrizante. Apesar disso, poucas comprovações científicas do verdadeiro efeito terapêutico desta planta medicinal foram produzidas. $\mathrm{O}$ objetivo desse trabalho foi avaliar $\mathrm{O}$ efeito do tratamento tópico com $C$. langsdorffii no processo de reparo quando um corpo estranho é o indutor da inflamação. Para isso, 60 camundongos da linhagem $\mathrm{BALB} / \mathrm{c}$ foram submetidos à incisão cirúrgica linear de $1 \mathrm{~cm}$ no dorso para realizar o implante de uma lamínula de vidro com $12 \mathrm{~mm}$ de diâmetro no tecido subcutâneo. Quatro tratamentos para a ferida foram estabelecidos: controle (C) tratado com solução salina estéril, controle veículo (CV) tratado com óleo mineral estéril, tratamento 1 (T1) tratado com diluição (v:v) de óleo mineral estéril e óleo de C. langsdorffii, tratamento 2 (T2) tratado com óleo de $C$. langsdorffii puro. As avaliações foram realizadas em períodos de tempo pré-determinados (1, 3, 5, 7 e 14 dias). Era possível perceber características da fase proliferativa como a reepitelização, a presença de fibroblastos e a neovascularização, porém os grupos tratados com o óleo ( $\mathrm{T} 1$ e T2) não apresentavam reepitelização aos três dias. Esses grupos aos 5 e 7 dias apresentavam no exame macroscópico maior intensidade de edema, hiperemia e permanência de crostas. Na microscopia, a reepitelização ainda não estava completa e a crosta era serocelular. Nos grupos C e CV, apesar de discreta, era predominante a presença de mononucleares, enquanto nos grupos T1 e T2 o infiltrado inflamatório era misto e com maior intensidade que nos outros grupos. Quatorze dias depois da incisão cirúrgica, os aspectos macroscópicos dos grupos $\mathrm{C}$ e CV eram semelhantes e os grupos T1 e T2, apesar de a ferida estar completamente fechada e sem crostas, a pele desses animais estava espessada e na derme do grupo T2 parecia ter fibrose mais acentuada do que nos outros grupos. Esses resultados demonstraram que o tratamento tópico com óleo de $C$. langsdorffii prejudicou o processo de reparação normal de ferida na presença de corpo estranho.

TERMOS DE INDEXAÇÃO: Copaifera langsdorffii, copaíba, cicatrização de ferida, antiinflamatório.

\section{INTRODUÇÃO}

Inúmeras drogas produzidas a partir de plantas medicinais são usadas na medicina alternativa como antiinflamatórios e cicatrizantes. Paradoxalmente, apesar de serem usadas de maneira cada vez mais abrangente e muitas vezes representarem o único recurso terapêutico de uma comunidade, elas têm o uso baseado apenas em conhecimentos populares, faltando o suporte de evidências experimentais que comprovem o potencial terapêuti$\mathrm{co}$, mecanismo de ação, toxicidade e os possíveis efeitos colaterais.
O óleo extraído da copaíba, Copaifera langsdorffii, apesar de ser amplamente comercializado e indicado para tratamento de feridas, e ainda, dito como um medicamento "milagroso" é mais um exemplo em que faltam conhecimentos científicos acerca do seu verdadeiro potencial terapêutico. Poucos trabalhos são encontrados na literatura disponível e nem todos trazem todas as informações necessárias, o que gera resultados duvidosos e controversos. Não bastasse a escassez de conhecimento, outros problemas também estão envolvidos na sua utilização como, por exemplo, a contaminação, a autenticidade e a mistura a outros óleos nas preparações comercializadas. Isso, além de alterar os efeitos esperados, pode colocar em risco a saúde dos consumidores.

A planta da qual se extrai o óleo de copaíba é uma leguminosa da família Caesalpiniaceae e pertence ao gênero Copaifera. O óleo de $C$. langsdorffii é líquido, transparente e avermelhado, formado por ácidos resinosos e substâncias voláteis. Paiva et al. (1998) atribuíram ao óleo-resina de Copaifera langsdorffii efeito protetor da mucosa gástrica. Aprofundando as investigações, Paiva et al. (2003) e Paiva et al. (2004) induziram a formação de colite através da aplicação de ácido acético em ratos e verificaram - ação antiinflamatória potente. Nessas ocasiões, atribuiu-se a atividade antiinflamatória ao diterpeno, ácido caurenóico, presente em $C$. langsdorffii, visto que esse ácido inibe a atividade de transcrição do Fator Nuclear - kB (NF-kB), uma importante molécula envolvida no processo de ativação celular na resposta imune inata (Castrillo et al. 2001).

Brito et al. (1998, 1999), em experimentos, avaliaram o efeito do óleo de $C$. reticulata na cicatrização por meio de aplicação tópica em feridas de ratos e puderam perceber, na análise macroscópica, que naquelas feridas tratadas com óleo, a cicatrização era mais tardia em relação ao grupo controle tratado com solução salina. Da mesma forma, na avaliação microscópica, os animais tratados com a planta medicinal apresentavam sinais de inflamação mais evidentes e com menos fibras colágenas. Por outro lado, Paiva et al. (2002) investigaram a atividade de cicatrização de ferida em ratos pelo estudo com $C$. langsdorffii e obtiveram resultados que permitiram afirmar os efeitos benéficos do óleo-resina desta espécie, justificando o uso tradicional para o tratamento de feridas.

O objetivo desse trabalho foi avaliar as atividades cicatrizantes e antiinflamatórias do óleo de Copaifera langsdorffii, por meio dos exames macro e microscópico da pele, e também pelo perfil de migração celular para corpo estranho.

\section{MATERIAL E MÉTODOS}

Foram utilizados 60 camundongos isogênicos, fêmeas da linhagem BALB/c, com idades de 2 a 3 meses, mantidos em condições ambientais apropriadas, evitando situações de estresse e risco sanitário. Os animais foram divididos em dois grupos, controle e tratado. Os animais do grupo tratado foram subdivididos em: CV (controle veículo) tratado com óleo mineral estéril; (T1) tratado com óleo da copaíba, Copaifera langsdorffii, 
e óleo mineral estéril na diluição de 1:1 e (T2) tratado com óleo de C. langsdorffii puro. O óleo da planta foi adquirido no Laboratório de Bioatividade de Plantas do Instituto de Patologia Tropical e Saúde Pública (IPTSP) da Universidade Federal de Goiás (UFG) depois de ter sido devidamente identificado. O tratamento tópico foi realizado diariamente, sempre no período da manhã, durante todo o tempo experimental. Para cada um dos tratamentos foram estabelecidos cinco diferentes pontos experimentais (P1, P3, P5, P7 e P14), sendo que esses pontos equivaliam ao dia correspondente da retirada da lamínula.

Antes do implante do corpo estranho, os animais foram anestesiados com Cloridrato de Tiazina e Cloridrato de Cetamina (Flecknell 1987), nas concentrações anestésicas recomendadas pelos laboratórios fabricantes. Após a anestesia foi realizada a tricotomia em uma área de aproximadamente $2 \mathrm{~cm}^{2}$ e a limpeza da pele com álcool $70 \%$. Posteriormente, foi realizada incisão transversal de $1 \mathrm{~cm}$ no plano dorsal da pele da região torácica e divulsão do tecido subcutâneo. Cada animal recebeu na região divulsionada uma lamínula circular $(12 \mathrm{~mm}$ de diâmetro) esterilizada. Após o implante, a incisão cirúrgica foi suturada com fio de náilon e recebeu tratamento de acordo com o protocolo estabelecido. Para os animais controle, a incisão cirúrgica após ter sido suturada com o mesmo tipo de fio de sutura foi tratada apenas com solução salina estéril, seguindo o mesmo protocolo. $\mathrm{O}$ fio de sutura permaneceu até o final do experimento em ambos os grupos.

As extrações das lamínulas e a coleta da pele para o exame histopatológico foram realizadas nos dias 1, 3, 5, 7 e 14 (pontos experimentais); para isso foi realizado deslocamento cervical, conforme normas do National Research Council (NRC). Procedeu-se corte paralelo à incisão cirúrgica para extração da lamínula do espaço subcutâneo e, posteriormente, um fragmento de pele dorsal contendo uma área aparentemente saudável e outra da lesão foram coletados e fixados em formol tamponado a $10 \%$, desidratados, diafanizados e incluídos em parafina (Luna 1968). Dos blocos foram realizados cortes histológicos de $5 \mathrm{~mm}$ de espessura e corados em HematoxilinaEosina (HE).

A avaliação do processo de reparação foi realizada através de macro e microscopia da pele de todos os animais do estudo. Macroscopicamente foram analisados os aspectos relacionados à cicatrização como o estado geral da ferida (Ótimo, Bom, Regular), o aspecto da ferida (aberta ou fechada e com ou sem crostas) e observações relacionadas com a inflamação da ferida, como a presença de edema e hiperemia que foram classificados em: 0 = ausente, 1 = discreto, 2 = moderado, 3 = intenso. Microscopicamente a avaliação foi feita no ponto exato de encontro das duas bordas da ferida cirúrgica linear. Foram avaliadas as três porções da pele, epiderme, derme e hipoderme, e também a camada muscular que forma o panículo carnoso. As três fases do processo de reparo (inflamatória, proliferativa e de remodelação) foram analisadas. As variáveis avaliadas foram: presença de crosta serocelular, necrose, infiltrado inflamatório, hemorragia, hiperemia, proliferação vascular, reepitelização da epiderme, hiperplasia da epiderme, proliferação fibroblástica, e presença de sinais de regeneração muscular. As avaliações foram sistematizadas de forma semiquantitativa: $(0,0)$ ausente, $(1,0)$ discreto, $(2,0)$ moderado e $(3,0)$ intenso. Alguns parâmetros foram representados apenas como presente ou ausente. Para a avaliação dos resultados da microscopia da pele foi calculada a mediana entre os grupos para cada um dos parâmetros avaliados.

\section{RESULTADOS}

No dia um, o aspecto macroscópico das lesões, tais como, a presença de crostas, edema e hiperemia, era similar em todos os animais. Na microscopia, foi possível notar que em todos os grupos as feridas cirúrgicas estavam cobertas por crostas formadas por debris celulares e fibrina, caracterizando material amorfo classificado como crosta serocelular. No primeiro dia, que corresponde ao início da fase inflamatória, pôde ser observada na macroscopia a presença de edema e hiperemia na pele de todos os animais. Na microscopia de luz as alterações inflamatórias também estavam presentes, o infiltrado inflamatório na derme e panículo carnoso era predominantemente polimorfonuclear em todos os grupos.

No terceiro dia, microscopicamente, já era possível perceber características da fase proliferativa como a reepitelização, presença de fibroblastos e neovascularização. Entretanto, as características da fase inflamatória persistiam em todos os grupos, como o infiltrado inflamatório, predominantemente polimorfonuclear e as alterações vasculares, como a hemorragia e hiperemia. Os grupos C e CV, apesar de possuírem crostas serocelular cobrindo a epiderme, apresentavam reepitelização fechando toda extensão da ferida. Já os grupos tratados com o óleo de Copaifera langsdorffii diluído em óleo mineral (T1) ou com o óleo de C. langsdorffii puro (T2) a reepitelização não foi percebida (Fig.1).

Avaliando as feridas cirúrgicas macroscopicamente aos cinco e sete dias, foi possível perceber que os animais tratados com o óleo, tanto no Grupo T1 quanto no T2, apresentavam edema e hiperemia de maior intensidade e permanência de crostas. Na microscopia apenas os Grupos C e CV já apresentavam a reepitelização completa com hiperplasia das células da epiderme. Os Grupos T1 e T2, além de apresentar reepitelização parcial, permaneciam com crostas sobre a epiderme, como é demonstrado na Fig.2. O infiltrado inflamatório se modificou aos cinco dias nos Grupos C e CV, pois, apesar de discreto, era predominante a presença de mononucleares, enquanto nos Grupos T1 e T2 as células inflamatórias foram encontradas aproximadamente na mesma proporção de mono e polimorfonucleares, e com maior intensidade que nos outros grupos, como pode ser observado no Quadro 1. Aos sete dias, as alterações vasculares eram similares entre os grupos, pois todos apresentavam hemorragia e hiperemia discreta, entretanto, os grupos que possuíam tratamento com o óleo (T1 e T2) apresentavam o infiltrado inflamatório mais acentuado (Quadro 2). Em todos os animais, independente do tratamento, o processo de reparo da camada muscular já apresentava miotubos com núcleos centrais e proliferação fibroblástica, caracterizando regeneração por brotamento do panículo carnoso.

No último ponto experimental, quatorze dias depois da incisão cirúrgica, os aspectos macroscópicos dos Grupos $\mathrm{C}$ e CV eram semelhantes, mas em relação aos Grupos T1 e T2, apesar da ferida estar completamente fe- 

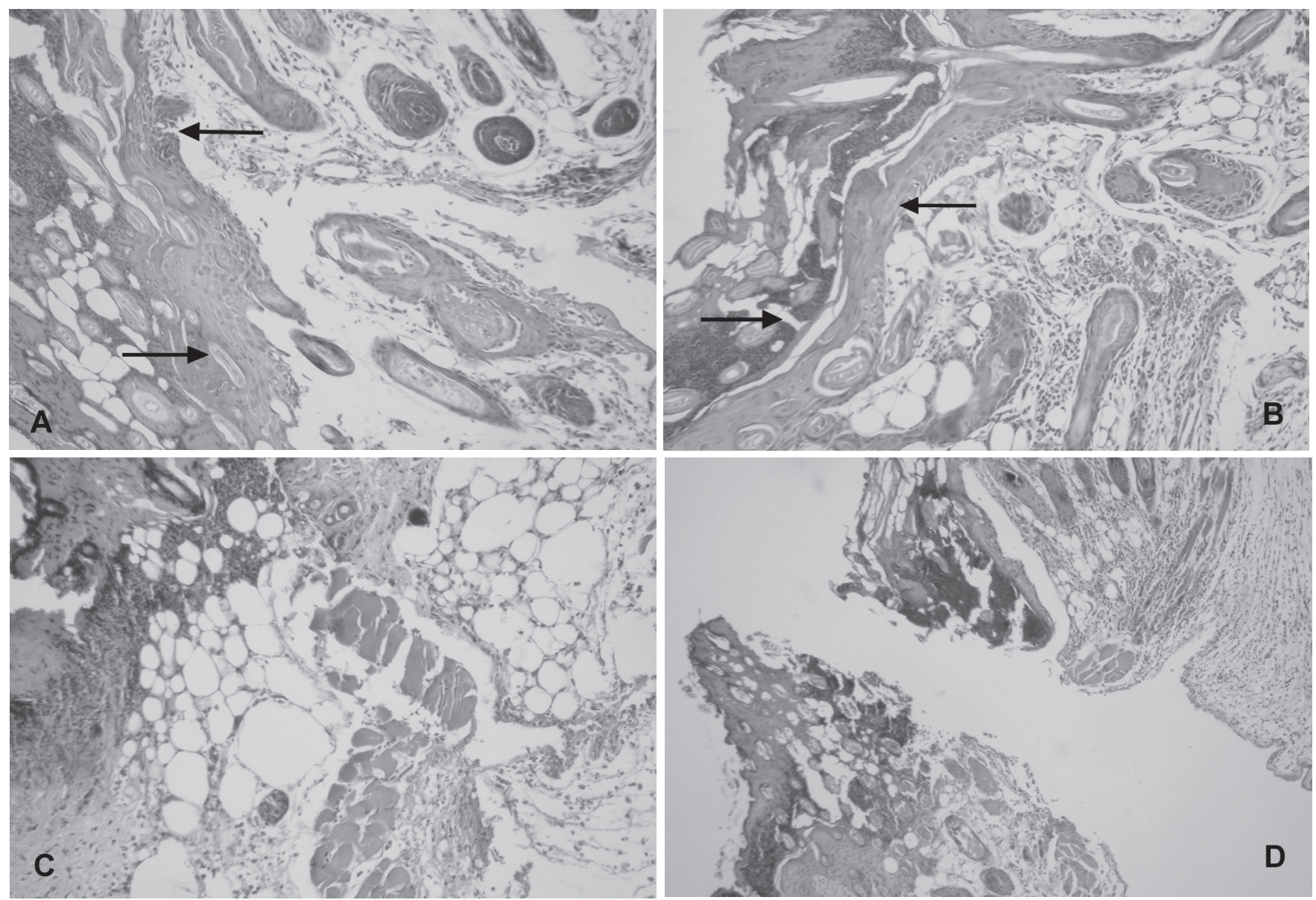

Fig.1. Pele de camundongos 3 dias após a incisão cirúrgica. (A) grupo controle, tratado topicamente com solução salina estéril, (B) grupo controle veículo, tratado com óleo mineral estéril, (C) grupo tratado 1, tratado com diluição (v:v) de óleo mineral estéril e óleo de Copaifera langsdorffii, e (D) grupo tratado 2, tratado com óleo de $C$. langsdorffii puro. Pode ser observada a presença de crosta serocelular na epiderme em todos os grupos, porém, nas imagens (A) e (B) nota-se a presença de reepitelização da epiderme abaixo da crosta (seta). Nas imagens (C) e (D) percebem se a falta de reepitelização. As imagens correspondem a um campo representativo de animal por grupo. HE, obj.10x (C, CV, T1) e obj.5x (T2).

chada e sem crostas, a pele desses animais estava espessada, principalmente no grupo tratado com o óleo puro (Grupo T2). Microscopicamente, o que pôde ser observado no Grupo T2 foram dobras na epiderme, mostrando certa desorganização do tecido de reparo (Fig.3). Além disso, o infiltrado inflamatório na derme era discreto nos Grupos C e CV e moderado nos outros grupos. Nessa fase, o processo de reparo já encontrava-se em remodelação e, por isso, quase não se observou hiperemia e proliferação vascular em nenhum dos grupos. Macro e microscopicamente

Quadro 1. Avaliação dermatohistológica após 5 dias de tratamento tópico das lesões cirúrgicas com solução salina estéril (C), óleo mineral estéril (CV), diluição (v:v) de óleo mineral estéril e óleo de Copaifera langsdorffii (T1) e óleo de $C$. langsdorffii puro (T2). Mediana de três animais por grupo

\begin{tabular}{|c|c|c|c|c|c|c|c|c|c|c|c|c|}
\hline \multirow[t]{2}{*}{ Dia 5} & \multicolumn{3}{|c|}{ C } & \multicolumn{3}{|c|}{ CV } & \multicolumn{3}{|c|}{ T1 } & \multicolumn{3}{|c|}{$\mathrm{T} 2$} \\
\hline & Epia & Der $^{b}$ & Mus $^{c}$ & Epi & Der & Mus & Epi & Der & Mus & Epi & Der & Mus \\
\hline Presença de crosta serocelular & - & - & - & - & - & - & 2,0 & - & - & 2,0 & - & - \\
\hline Necrose & 0,0 & 0,0 & 0,0 & 0,0 & 0,0 & 0,0 & 0,0 & 0,0 & 0,0 & 0,0 & 0,0 & 0,0 \\
\hline Infiltrado mononucleares & 0,0 & 1,0 & 1,0 & 0,0 & 1,0 & 1,0 & 0,0 & 3,0 & 2,0 & 0,0 & 2,0 & 2,0 \\
\hline Filtrado polimorfonucleares & 0,0 & 0,0 & 0,0 & 0,0 & 0,0 & 0,0 & 0,0 & 2,0 & 2,0 & 0,0 & 2,0 & 1,0 \\
\hline Hemorragia & 0,0 & 1,0 & 0,0 & 0,0 & 1,0 & 0,0 & 0,0 & 1,0 & 0,0 & 0,0 & 2,0 & 1,0 \\
\hline Hiperemia & - & 1,0 & 1,0 & - & 1,0 & 1,0 & - & 2,0 & 2,0 & - & 2,0 & 2,0 \\
\hline Proliferação vascular & - & 1,0 & 1,0 & - & 0,0 & 1,0 & - & 1,0 & 1,0 & - & 1,0 & 1,0 \\
\hline
\end{tabular}

aEpiderme, ${ }^{\mathrm{b}}$ derme, ${ }^{\mathrm{c}}$ muscular (panículo carnoso). 

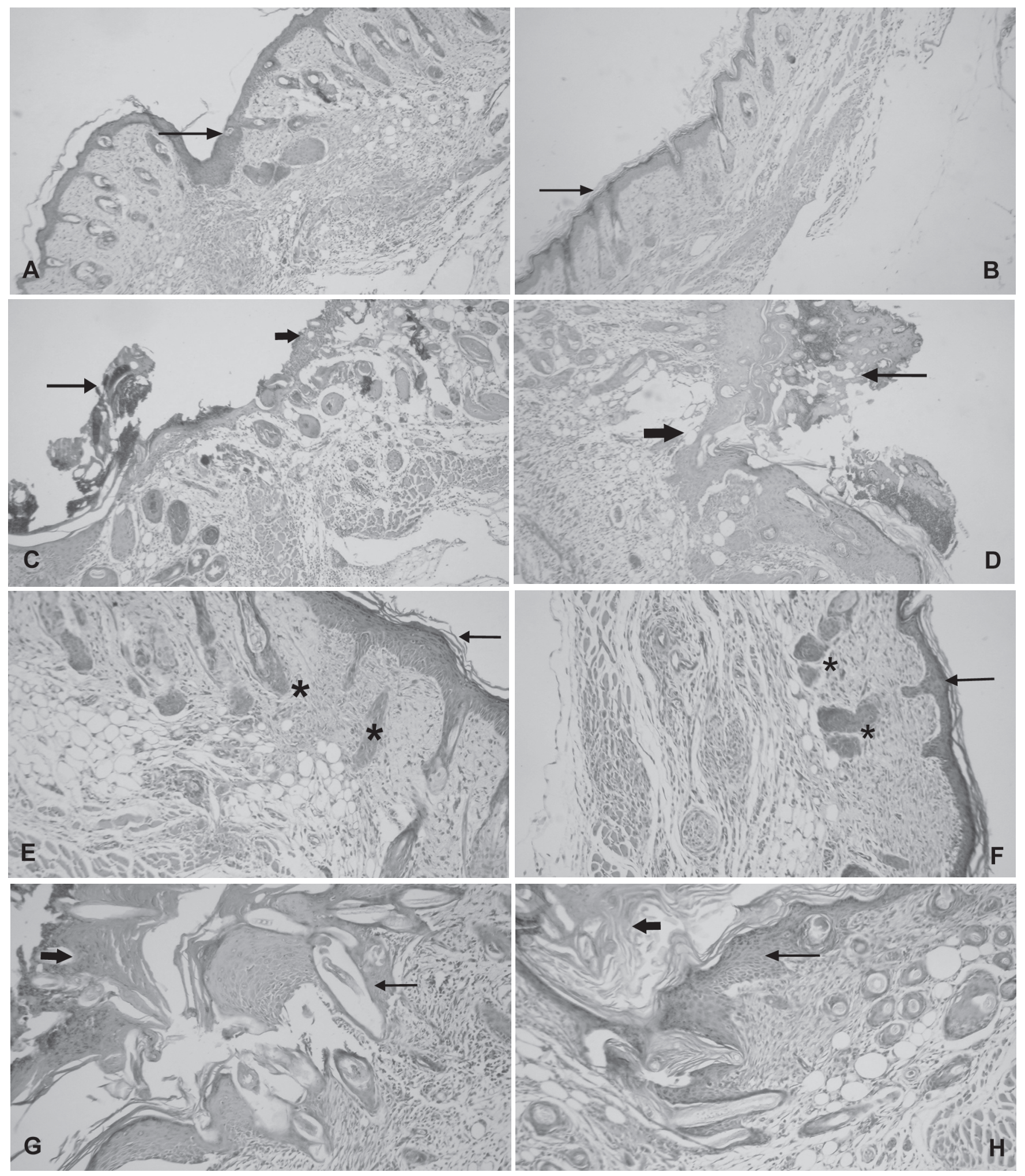

Fig.2. Pele de camundongos 5 e 7 dias após a incisão cirúrgica. $(A)$ e (E) grupo controle, tratados topicamente com solução salina estéril, (B) e (F) grupo controle veículo, tratados com óleo mineral estéril, (C) e (G) grupo tratado 1, tratados com diluição (v:v) de óleo mineral estéril e óleo de Copaifera langsdorffii, e (D) e (H) grupo tratado 2, tratados com óleo de C. langsdorffii puro. As imagens de (A) a (D) correspondem ao dia 5 e de $(E)$ a $(H) 7$ dias. Note como $(A),(B),(E)$ e $(F)$ apresentam a incisão completamente reepitelizada, sem áreas de crostas sobre a epiderme (seta). Nas imagens (C), (D), (G) e (H) ainda não havia reepitelização total (seta larga), havia presença de crostas serocelular (seta) sobre a epiderme. *Presença de anexos. As imagens correspondem a um campo representativo de um animal por grupo. HE, obj.10x 
Quadro 2. Avaliação dermatohistológica após sete dias de tratamento tópico das lesões cirúrgicas com solução salina estéril (C), óleo mineral estéril (CV), diluição (v:v) de óleo mineral estéril e óleo de Copaifera langsdorffii (T1) e óleo de C. langsdorffii puro (T2). Mediana de três animais por grupo

\begin{tabular}{|c|c|c|c|c|c|c|c|c|c|c|c|c|}
\hline \multirow[t]{2}{*}{ Dia 7} & \multicolumn{3}{|c|}{$\mathrm{C}$} & \multicolumn{3}{|c|}{ CV } & \multicolumn{3}{|c|}{$\mathrm{T} 1$} & \multicolumn{3}{|c|}{$\mathrm{T} 2$} \\
\hline & Epi ${ }^{\mathrm{a}}$ & $\operatorname{Der}^{\mathrm{b}}$ & Mus $^{c}$ & Epi & Der & Mus & Epi & Der & Mus & Epi & Der & Mus \\
\hline Presença de crosta serocelular & - & - & - & - & - & - & 2,0 & - & - & 2,0 & - & - \\
\hline Necrose & 0,0 & 0,0 & 0,0 & 0,0 & 0,0 & 0,0 & 0,0 & 0,0 & 0,0 & 0,0 & 0,0 & 0,0 \\
\hline Infiltrado mononucleares & 0,0 & 1,0 & 1,0 & 0,0 & 1,0 & 1,0 & 0,0 & 3,0 & 2,0 & 0,0 & 2,0 & 2,0 \\
\hline Filtrado polimorfonucleares & 0,0 & 0,0 & 0,0 & 0,0 & 0,0 & 0,0 & 0,0 & 0,0 & 0,0 & 0,0 & 0,0 & 0,0 \\
\hline Hemorragia & 0,0 & 1,0 & 0,0 & 0,0 & 0,0 & 0,0 & 0,0 & 1,0 & 0,0 & 0,0 & 1,0 & 0,0 \\
\hline Hiperemia & - & 1,0 & 1,0 & - & 1,0 & 1,0 & - & 1,0 & 1,0 & - & 1,0 & 1,0 \\
\hline Proliferação vascular & - & 1,0 & 1,0 & - & 1,0 & 1,0 & - & 1,0 & 1,0 & - & 1,0 & 1,0 \\
\hline
\end{tabular}

aEpiderme, ${ }^{b}$ derme, ${ }^{c}$ muscular (panículo carnoso).
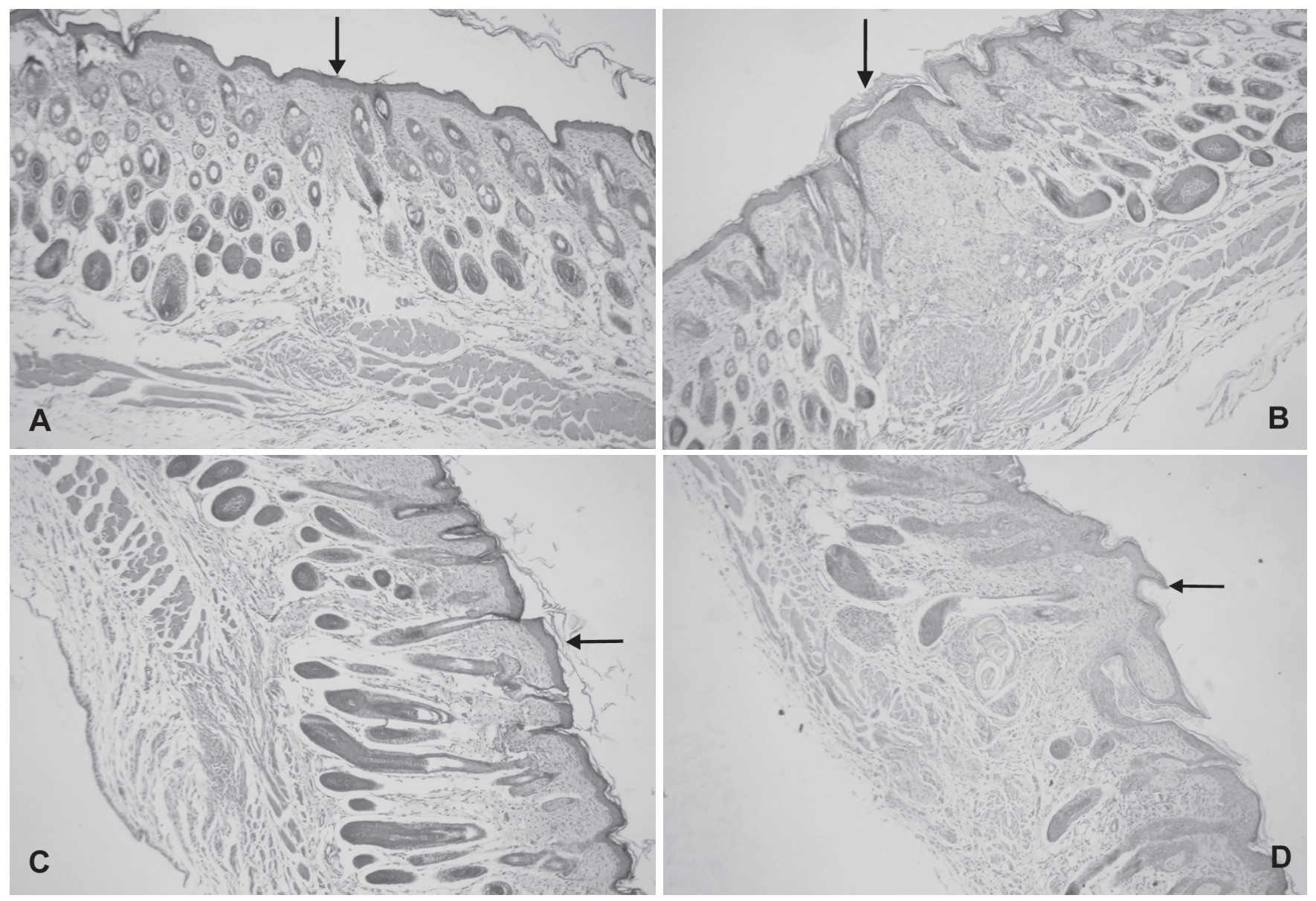

Fig.3. Pele de camundongos 14 dias após a incisão cirúrgica. (A) grupo controle, tratado topicamente com solução salina estéril, (B) grupo controle veículo, tratado com óleo mineral estéril, (C) grupo tratado 1, tratado com diluição (v:v) de óleo mineral estéril e óleo de Copaifera langsdorffii, e (D) grupo tratado 2, tratado com óleo de C. langsdorffii puro. Note na área da incisão cirúrgica (seta) a desorganização na epiderme dos grupos T1 e T2. Na imagem (D), nota-se que existem dobras na epiderme e derme. As imagens correspondem a um campo representativo de animal por grupo. HE, obj.5x.

o local da incisão já era praticamente imperceptível em relação à área saudável, porém a derme do Grupo T2, aparentemente, apresentava na microscopia fibrose mais acentuada do que nos outros grupos. Todos os grupos, independente do tratamento, possuíam sinais de regeneração e fibrose na camada muscular (Fig.4).

\section{DISCUSSÃO}

Os resultados apresentados em camundongos demonstram que, a utilização do óleo de Copaifera langsdorffii no tratamento de feridas cirúrgicas, gerou um efeito deletério em tratamentos cutâneos. Ou seja, as feridas cirúrgicas com cicatrização de primeira intenção tratadas com o 


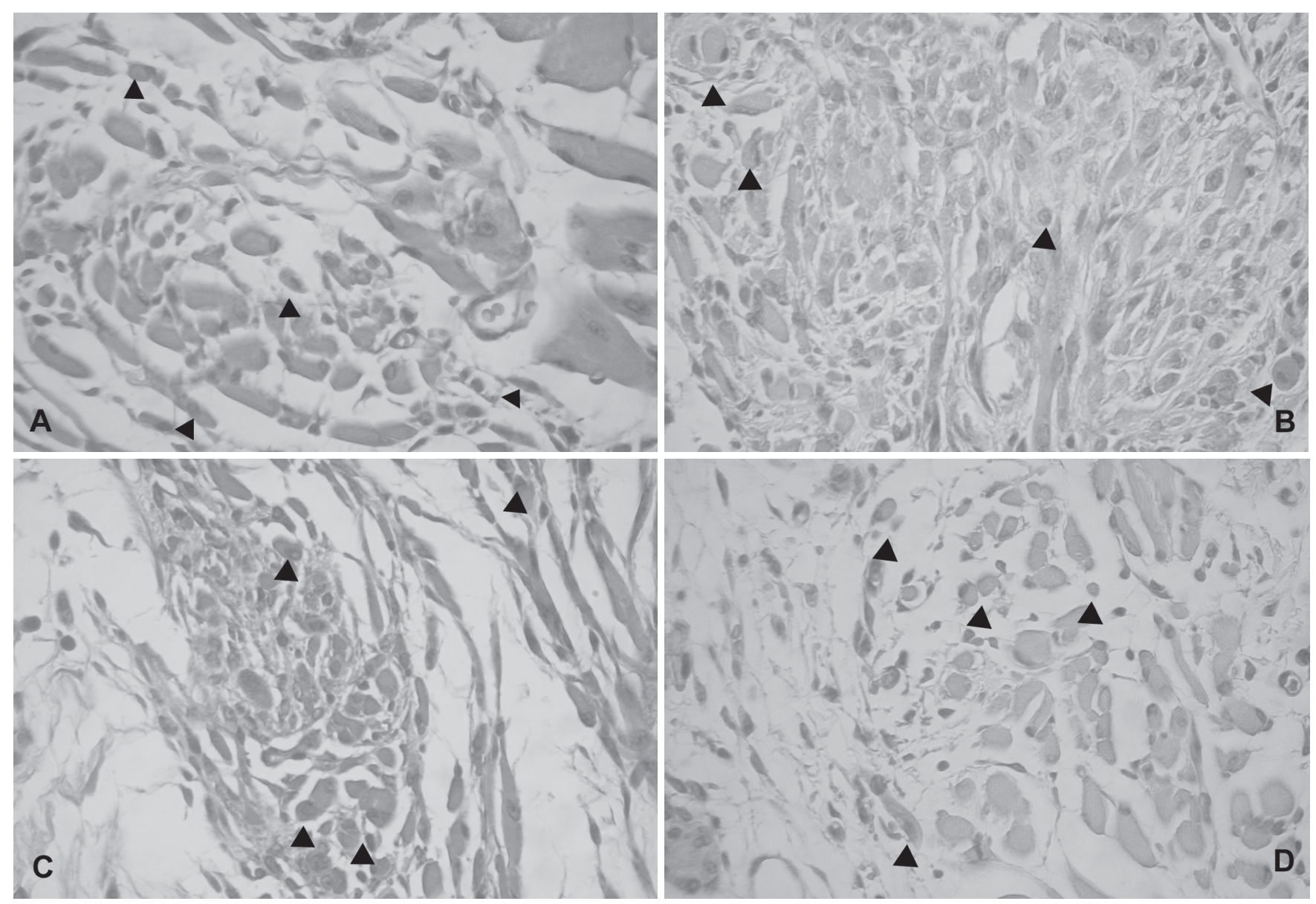

Fig.4. Processo de reparo do panículo carnoso de camundongos 14 dias após a incisão cirúrgica. (A) grupo controle, tratado topicamente com solução salina estéril, (B) grupo controle veículo, tratado com óleo mineral estéril, (C) grupo tratado 1, tratado com diluição (v:v) de óleo mineral estéril e óleo de Copaifera langsdorffii e (D) grupo tratado 2, tratado com óleo de $C$. langsdorffii puro. Todos os grupos apresentavam reparo do panículo carnoso com proliferação de fibroblastos e regeneração de miotubos. Note a presença de fibrose, como na fotomicrografia $(B)$, e miotubos delgados (cabeça de seta) e alguns deles com núcleos centrais $(A, B, C$ e $D)$. As imagens correspondem a um campo representativo de animal por grupo. HE, obj.40x.

óleo de $C$. langsdorffii apresentaram retardo no processo de reepitelização, permanência de crostas e ainda a persistência das alterações vasculares e inflamatórias.

Quando a epiderme foi avaliada pôde-se perceber que, camundongos tratados com o óleo de $C$. langsdorffii, apresentavam dificuldade no restabelecimento da continuidade do epitélio e também permaneciam por mais tempo com a crosta serocelular no local da ferida. Os achados microscópicos do presente experimento demonstraram que, apesar de o aspecto macroscópico da ferida linear estar fechado, a epiderme não estava completamente formada, o que poderia facilitar contaminações e, possível, deiscência de ferida. Segundo Martinez-Hernandez (2002), a reepitelização tem um importante papel no processo de reparação, pois através da proliferação e hiperplasia das células epiteliais a continuidade do tecido é restabelecida. Aos quatorze dias, todos os grupos apresentavam fechamento completo da epiderme, porém o grupo T2 possuía dobras na camada epitelial e desorganização do tecido cicatricial. Esse mesmo grupo possuía mais fibrose no local da incisão, assim como uma ferida com maior dificuldade de controlar a produção e remodelação do colágeno, devido a alguma desordem na formação do tecido de granulação como sugerido por Mandel baum et al., (2003). A presença de crosta nos Grupos T1 e T2 durante um período mais longo nas lesões foi um fato marcante nos resultados. De acordo com Muller \& Kirk's (1995), crosta é uma massa ressecada e consolidada na superfície da ferida, composta de uma combinação de queratina, soro, debris celulares e, freqüentemente, restos de microorganismos. Quando esta se apresenta formada principalmente por soro e restos de células inflamatórias deve ser chamada de crosta serocelular. No exame histopatológico da pele aos cinco dias, além da reepitelização parcial da epiderme e da presença de crosta serocelular sobre a incisão, na derme dos animais tratados com óleo, também era maior a incidência de células inflamatórias e alterações vasculares, como hemorragia e hiperemia. Macroscopicamente, a pele dos animais do Grupo T1 e T2 mantiveram sinais inflamatórios como, 
edema e hiperemia, que persistiram até o sétimo dia do processo.

Esta permanência da fase inflamatória pode estar associada à presença de crostas e conseqüente falta da reconstituição da epiderme, podendo facilitar a contaminação da ferida. Em virtude da presença de microorganismos o sistema imune inato permanece ativado, mais células migram em direção ao foco da lesão e mais citocinas proinflamatórias são produzidas. Essas células secretam constantemente quimiocinas para atrair mais células inflamatórias e substâncias vasoativas, além de radicais reativos de oxigênio e nitrogênio, que são lançados no microambiente da inflamação. Além disso, o influxo de neutrófilos e macrófagos para essa região aumenta a demanda por oxigênio, com conseqüente elevação das concentrações de ácido lático e queda do pH. Essa combinação de hipóxia, baixo pH e altas concentrações de ácido lático ativa os macrófagos para a síntese de fatores de crescimento, como o TGF-â, um importante estimulador de síntese de matriz extracelular e proliferação fibroblástica, porém que interfere de forma negativa na reepitelização (Balbino et al. 2005).

Corroborando nossos dados, Brito et al. (1998) e Brito et al. (1999), avaliando em ratos a macro e microscopia de feridas tratadas com o óleo de Copaifera reticulata, encontraram persistência de hiperemia até os quatorze dias, maior área das feridas e a permanência de crostas por um período mais longo do que nos animais controle tratados com solução salina. Esses autores relatam que as lesões de pele que receberam o óleo puro estavam cobertas por material de espessura variável, constituída de leucócitos, restos de hemácias e fibrina. Além disso, apresentavam retardo na reepitelização, maior quantidade de células inflamatórias e hiperemia dos vasos sanguíneos. Essas alterações estavam presentes em nossos resultados, em maior ou menor grau, de acordo com o estágio da ferida e o tipo de tratamento realizado. Apesar de se tratar de espécies diferentes do gênero Copaifera, os resultados encontrados são similares, o que talvez seja pelo fato de ambas as espécies terem proximidades na constituição química, como foi verificado por Veiga Jr \& Pinto (2002).

Apenas um estudo, com o objetivo de avaliar a influência de $C$. langsdorffii no processo de cicatrização, foi encontrado na literatura correlata. Esse estudo foi realizado por Paiva et al. (2002), os quais avaliaram a contração e a força de tensão da ferida em ratos. Estabeleceram tratamentos diários com solução salina para o controle e duas concentrações diferentes do óleo ( $2 \%$ e $4 \%$ ) para os tratamentos. Dois diferentes modelos de feridas foram produzidos, uma completa de $2 \mathrm{~cm}^{2}$ e outra linear de $4 \mathrm{~cm}$. Os resultados mostraram que o tratamento com o óleo aumentou a força de tensão e a contração da ferida nos dias nove e cinco de tratamento, sendo que nos outros dias de avaliação não houve diferença entre os grupos. Esses autores não descreveram as alterações macro e microscópicas das lesões, e assim mesmo, rela- cionaram seus resultados à formação de tecido de granulação e à ação de miofibroblastos. Além disso, concluem que o tratamento com o óleo pode ter um efeito benéfico, pois evita complicações de deiscência da ferida.

Com base nas literaturas consultadas, a presença de polimorfos e mononucleares tem se mostrado de forma diferente de acordo com a concentração do tratamento, via de administração e órgão alvo. Nossos resultados demonstraram que o infiltrado inflamatório na pele, tanto dos animais tratados com o óleo de $C$. langsdorffii diluído em óleo mineral (v:v) quanto daqueles tratados com o óleo de $C$. langsdorffii puro, nos dias cinco e sete de tratamento, apresentava-se mais intenso do que nos Grupos $\mathrm{C} \mathrm{e}$ CV. Paiva et al. (2002) e Paiva et al. (2004) administrando por via oral o óleo de $C$. langsdorffii em diferentes concentrações, ou o ácido caurenóico, um diterperno presente neste óleo, para ratos com colite induzida por ácido acético, mostraram que os animais tratados apresentavam menor infiltrado inflamatório na submucosa gástrica. Nestas ocasiões esses autores atribuíram a atividade antiinflamatória ao ácido caurenóico do óleo de $C$. langsdorffii, pois segundo Castrillo et al. (2001), esse diterpeno caureno inibe a atividade de transcrição do Fator Nuclear- kB (NF-kB), uma importante molécula envolvida no processo de ativação de macrófagos.

Um fato comum a todos os grupos foi o tipo de reparo que ocorreu no panículo carnoso. O desenvolvimento dessa reparação seguiu as fases descritas por McGavin (1998), ou seja, degeneração, necrose e regeneração. Apesar de a degeneração e a necrose, devido à incisão cirúrgica, terem variado entre discretas e moderadas, a evolução da reparação do músculo não foi influenciada pelos tratamentos. No local da reparação da musculatura pôde-se observar a proliferação de fibroblastos e também sinais de regeneração por brotamento, com a presença de células gigantes musculares, formação de miotubos delgados e disposição de núcleos centrais, porém nem sempre esse processo pôde ser avaliado com clareza, uma vez que o tecido muscular é facilmente afetado por artefatos de técnicas, como afirmaram McGavin (1998) e Mclnnes (2005).

Para Rodella et al. (2006), a presença de um corpo estranho no tecido faz com que macrófagos deixem de se envolver na cicatrização normal e passem a exercer a função de reconhecer superfícies estranhas, rompendo a seqüência de eventos do processo de reparo do tecido lesado. Entretanto, os resultados aqui apresentados mostraram que, apesar de existir uma lamínula no espaço subcutâneo próximo à incisão, a morfologia do tecido e o desenvolvimento do processo de reparo não foram alterados, estando as diferenças encontradas entre os grupos associadas ao tratamento e não a presença de corpo estranho.

\section{CONCLUSÃO}

Os exames histopatológicos de pele, em camundongos $\mathrm{BALB} / \mathrm{c}$ que tiveram as feridas cirúrgicas submetidas a 
diferentes tratamentos, permitiram concluir que o uso do óleo de Copaifera langsdorffii para tratamento tópico de feridas cirúrgicas influencia de forma negativa o processo de reparação, aumentando o tempo de restabelecimento da continuidade da epiderme.

Agradecimentos.- À Coordenação de Aperfeiçoamento de Pessoal de Ensino Superior e ao Programa de Pós-Graduação da Escola de Veterinária, Universidade Federal de Goiás (UFG), ao Conselho Nacional de Desenvolvimento Científico e Tecnológico e à Fundação de Apoio à Pesquisa da UFG.

\section{REFERÊNCIAS}

Balbino C.A., Pereira L.M. \& Curi R. 2005. Mecanismos envolvidos na cicatrização: uma revisão. Revta Bras. Ciênc. Farm. 41(1):27-51.

Brito N.M.B., Simões M.J., Pessoa A.F. \& Melo M.C.F. 1998. Efeitos do óleo de copaíba na cicatrização de feridas cutâneas abertas de ratos. Revta Paraense Med. 12(1):28-32.

Brito N.M.B., Simões M.J., Gomes P.O., Pessoa A.F. \& Melo M.C.F. 1999. Aspectos microscópicos da cicatrização de feridas cutâneas abertas tratadas com óleo de copaíba em ratos. Revta Paraense Med. 13(1):12-17.

Castrillo A., Heras B., Hortelano S., Rodriguez B., Villar A. \& Boscá L. 2001. Inhibition of the nuclear Factor kB (NF-kB) pathway by Tetracyclic Kaurene Diterpenes in macrophages. J. Biol. Chem. 276(19):1585415860.

Flecknell P.A. 1987. Laboratory Animal Anaesthesia: An introduction for research workers and technicans. Academic Press, London, p.156.

Luna L.G. 1968. Manual of Histologic Staining Methods of the Armed Forces Institute of Pathology. 3rd ed. McGraw-Hill, New York, p.258.

Mandelbaum S.H., DiSantis E.P. \& Mandelbaum M.H.S. 2003. Cicatri- zação: conceitos atuais e recursos auxiliares. Parte I. Anais Bras. Dermatol. 78(4):393-410.

Martinez-Hernandez A. 2002. Reparo, regeneração e fibrose, p.74-101. In: Rubin E. \& Farber J.L. (ed.), Patologia. $3^{\underline{a}}$ ed. Guanabara Koogan, Rio de Janeiro.

McGavin M. D. 1998. Músculos, p.417-445. In: Carlton W.W. \& McGavin M.D. (ed.), Thomson's Patologia Veterinária Especial. $2^{\underline{a}}$ ed. Editora Artes Médicas Sul, Porto Alegre.

Mclnnes E. 2005. Artefacts in histopathology. Comp. Clin. Pathol. 13(1):100-108.

Muller G.H. \& Kirk's R.W. 2000. Small Animal Dermatology. 6th ed. W.B. Saunders, Philadelphia, p.1552.

Paiva L.A.F., Rao V.S.N., Gramosa N.V. \& Silveira E.R. 1998. Gastroprotective effect of Copaifera langsdorffii oleo-resin on experimental gastric ulcer models in rats. J. Ethnopharmacol. 62(1):73-78.

Paiva L.A., Cunha K.M.A., Santos F.A., Gramosa N.V., Silveira E.R. \& Rao V.S.N. 2002. Investigation on the wound healing activity of oleoresin from Copaifera langsdorffii in rats. Phytother. Res. 16(1):737-739.

Paiva L.A.F., Gurgel L.A., Silva R.M., Tomé A.R., Gramosa N.V., Silveira E.R., Santos F.A. \& Rao V.S.N. 2003. Anti-inflammatory effect of kaurenoic acid, a diterpene from Copaifera langsdorffii on acetic acidinduced colitis in rats. Vascul. Pharmacol. 39(1):303-307.

Paiva L.A.F., Gurgel L.A., De Souza E.T., Silveira E.R., Silva R.M., Santos F.A. \& Rao V.S.N. 2004. Protective effect of Copaifera langsdorffii oleo-resin against acetic acid-induced colitis in rats. J. Ethnopharmacol. 93(1):51-56.

Rodella L.F., Rezzani R., Buffoli B., Bobomini F., Tengattini S., Laffranchi L., Paganelli C., Sapelli P.L. \& Bianchi R. 2006. Role of mast cells in wound healing process after glass-fiber composite implant in rats. J. Cell Mol. Med. 10(4):946-954.

Veiga Junior V.F. \& Pinto A.C. 2002. O gênero Copaifera L. Química Nova 25(2):273-286. 